\title{
Research and Discuss on Market model based on Blockchain
}

\author{
YAN Cui-hui ${ }^{1}$, LIU Fang ${ }^{1}$, HU Chaofan ${ }^{2}$, CUI Hui ${ }^{1}$ and WANG Bin $^{2}$ \\ ${ }^{1}$ Power System Automation Department, China Electric Power Research Institute, Haidian District, Beijing \\ ${ }^{2}$ National Power Dispatching and Control Center, State Grid Corporation of China, Beijing, China
}

\begin{abstract}
Electric power industry is the foundation of national economy and plays a key role in the development of human society. Traditional power industry is monopolized by industry and lacked of market efficiency. In recent years, it is seeking breakthroughs in the market-oriented reform. Although China's electricity market reform has achieved some achievement, it is still lacked of market players, regional transactions, excessive data management, concentration and other defects. This paper puts forward higher requirements for the system design of power market transactions. The electrical power market is facing with the security and performance challenges, it is to improve the electrical power market transaction mode and to enhance transaction security, blockchain is a new decentralized framework and with a distributed computing paradigm, which integrates and innovates a variety of computer technologies, then it constructed a perfect competitive electricity market system. Using of different levels of multi auction trading model to integrate the province's trading and inter provincial trading parts in one system. In the part of inter-province trading, it adopted the contract trading and bidding coexist pattern, the trade is carried out in each province Surplus-deficit electricity which based on the meet of the province's demand basis. By using blockchain, it can conducted the intelligent contract and record the whole transaction information discretely, and provided the inquiry transaction channel to the users, so it can achieve the resource scheduling fairness and transaction information in security.
\end{abstract}

\section{Introduction}

Electrical power market reform has initiated in China since 2000, and it have made experiments in several provinces, it realized the separation of plant and network and achieved the competitive bidding construction of sell side market as in refers [1], the electricity market trading volume increased rapidly over the past two years, the total electricity consumption has gone up to $20 \%$ through market transactions in 2016 [2]. However, there are still some problems in the electricity market, for example, the power trading is mainly concentrated of the province market and the management mode is over centralization [3]. On the one hand, its results in the existing electricity market is difficult to meet the market demand, on the other hand, the centralized data management leaded to the low data security and credibility, which also prejudice the development of market integration and resource allocation [4]. In order to solve the above shortcomings, it is necessary to seek a decentralization platform technology to support large-scale regional electricity market transactions and more secure and reliable transaction data storage. Using the new emerging decentralization technology of blockchain, the problems in current power market transactions can be much better solved.

\section{BlockChain}

\subsection{Brief Introduction of electricity market}

Electricity market is a place or platform where the buyer and seller of electricity interact with each other, then to determine the clearing price and quantity, it has competitive and open characters, then mainly configure the power resources using market measure. As in refers [5] it is a new type of power operation mode based on fair competition among electrical power enterprises, which can effectively reduce power production cost and raise production efficiency.

The existing electricity trading patterns differences mainly focused on whether Power Grid Corp involved in electricity transactions or responsible for power transmission only [6]. Most of the world countries adopted the free market model in early, which Power Grid Corp is only responsible for power transmission. In American model [7], the Power Grid Corp is not take part in the purchase and sale of electricity business, which only in charge of power grid management and wheeling charge [8]. Canada mainly used the power generation and sale link independent mode, it is monopolized of the Power Grid Corp operating in the transmission and distribution sectors, but in the end of power production 
bidding bringing in competition, then in the customers right brought in market competition and open the clientele choose independently[9]. India and Brazil mainly adopted the transmission and consumption link independent mode, Power Grid Corp did not participate in market transactions only introduced competition on the power generation side [10]. In the Commonwealth model, the national electrical power company possessed all the power transmission networks, and did not participating in the market of the power generation and the selling side, which fully introduced the market competition [11]. Northern Europe adopted centralized operation and market mode at the same time, where the power generation companies and power users can complete the transaction on the self-supporting power transmission and distribution network, and also can charge net service fees by the Power Grid Corp [12]. In the Argentina electricity market model, it has more realized the independence of all aspects of electricity market links thoroughly such as the generation, transmission, distribution and selling, the Power Grid Corp has completely not participated in the electricity market transactions as in refers [10]. Only Japan considered energy security and its specific conditions, it still used integrated system of power supply, transmission and distribution as referred in [10] [13] [14].

China power industry reform has experienced the stages of complete monopoly, "collecting funds for electricity”, simulating electric power market, electricity market pilot, "generation and network separation" reform and regional electricity market pilot operation stages in refers [15]. Since the 2015 electricity reform No. 9 release as in refers [16], the State Grid is implemented the market-oriented reform of the power grid, it aims to achieve a competitive electricity market, which can orderly liberalization the electricity price of competitive aspects and the power plan outside of public welfare adjustment, it can strengthen the electricity market platform and voluntary and increase the inter provincial and cross regional market transactions, then enhance market efficiency and promote the power resources configuration optimally in market regulation and in a larger scope, it can improve the network operation efficiency and power supply service level as in refers [17]. According to the policy reform and market construction of several pilot provinces, the typical power trade methods and trading power of several provinces is shown in table I [18].

Table 1. Typical provinces electricity markets trading methods and electricity

\begin{tabular}{|c|l|c|c|}
\hline Province & Transaction mode & $\begin{array}{l}\text { 2016year } \\
\text { transaction } \\
\text { power }\end{array}$ & $\begin{array}{c}\text { electricity } \\
\text { proportion } \\
\text { consumed in } \\
\text { this province }\end{array}$ \\
\hline \multirow{5}{*}{ Guang dong } & $\begin{array}{l}\text { Bilateral } \\
\text { consultations (long } \\
\text { association) and } \\
\text { monthly centralized } \\
\text { bidding }\end{array}$ & $\begin{array}{c}43 \text { billion } \\
980 \\
\text { million } \\
\mathrm{kwh}\end{array}$ & $8.06 \%$ \\
\hline Shan dong & $\begin{array}{l}\text { Bilateral } \\
\text { consultations, } \\
\text { centralized bidding } \\
\text { and listing Trading }\end{array}$ & $\begin{array}{c}129 \mathrm{billion} \\
509 \\
\text { million } \\
\mathrm{kwh}\end{array}$ & $24.02 \%$ \\
\hline
\end{tabular}

\begin{tabular}{|c|l|c|c|}
\hline Province & \multicolumn{1}{|c|}{ Transaction mode } & $\begin{array}{l}\text { 2016year } \\
\text { transaction } \\
\text { power }\end{array}$ & $\begin{array}{c}\text { electricity } \\
\text { proportion } \\
\text { consumed in } \\
\text { this province }\end{array}$ \\
\hline Shan xi & $\begin{array}{l}\text { Off-site bilateral } \\
\text { (multilateral) } \\
\text { consultations, on-site } \\
\text { bidding (including } \\
\text { match), floor listing } \\
\text { Trading }\end{array}$ & $\begin{array}{c}11 \text { billion } \\
90 \text { million } \\
\text { kwh }\end{array}$ & $6.17 \%$ \\
\hline An hui & $\begin{array}{l}\text { Bilateral trading and } \\
\text { centralized trading }\end{array}$ & $\begin{array}{c}39 \text { billion } \\
200 \\
\text { million } \\
\text { kwh }\end{array}$ & $21.84 \%$ \\
\hline Si chuan & $\begin{array}{l}\text { Autonomous bilateral } \\
\text { trading and } \\
\text { centralized trading }\end{array}$ & $\begin{array}{c}\text { Not yet } \\
\text { carry out } \\
\text { the sale of } \\
\text { electricity } \\
\text { business }\end{array}$ & \\
\hline Jiang xi & $\begin{array}{l}\text { Bilateral trading } \\
\text { oriented, centralized } \\
\text { trading as a } \\
\text { supplement }\end{array}$ & $\begin{array}{c}15 \text { billion } \\
\text { kwh }\end{array}$ & $12.69 \%$ \\
\hline \multicolumn{2}{|c|}{$/$} \\
\hline
\end{tabular}

\subsection{Problems in the current Electricity Market}

Although the development plan described in the previous section has many advantages [19][20], the current pilot electricity market model still has defects in considerable degree. On one hand, the management mode is over centralized; on the other hand, the market body lacks the regional electricity market[21].

The current mainstream electricity trading is mainly based on the main center operation mode, which can be operated normally in the case of government unified pricing, it will lead to the management of electricity trading increasingly much more and the information out of sync after the introduction of market factors. First of all, the data amount and real-time demand produced in the electricity trading would increasing times, there would be needed large number of manpower to maintain the central data and the trading clearing process, but the manual operation caused the trading clearing process inefficiently and trade confirmation delay. Secondly, according to the development of distributed generation technology, it will cause the electric bilateral trade mode produced because of mass generator and consumers brought in, and the original model cannot support the demand as well. Finally, once the organization attacked, the data can be lose or tampered, the excessive centralization will lead to the information out of sync, user' privacy faced threat and may appeared the condition of using central authority to damage the participant interests. Therefore, we need to find a decentralized, dynamic transaction data, and a high degree of automation technology to support the operation of the new electricity market trading platform as in refers [22] [23].

From the point of market players, all kinds of pilot are taking the province as market main body. Considering of the market development and resources allocation, it would lay a hidden danger for the future of market development. From the point of the future development model, the proportion of market is still small although the electricity consumption between provinces increased. Taking the power industry overall situation of 2017 year 
in 1-3 for example, the electricity sent out of each provinces including regional market trading taking up to 14.9 proportion in country total electricity consumption, the cross-district delivery electricity only accounted for 5.12 proportion of total [24]. It can be assumed that the amount of transmission electricity coming from electricity market trade would much less than this value. Most of china's electricity market is still limited to inner provinces dispatching and inter-provinces dispatching which center is based on the State Grid and South China power Grid, it caused the weak connection between various regions, when the inter province market over centralized, it would lead to market rigidity easy and then bring about administrative interference and local protection problems, so it is difficult for the market to play a role in system regulatory, the operation efficiency is far less than the regional electricity market [5]. From the point of resources allocation, the energy distribution and load demand between each provinces has bigger differences, the supply and demand in province is imbalance. In the provincial market system solidified condition, it is easy to produce the provincial barriers, then can limited the trade volume between provinces resources and restricted the industrial development [25].

In conclusion, the problems exited in current pilot electricity market model is as follows:

First, the management methods is much more concentrated, it lead to the difficulty to trade conduct and data storage increased greatly. Meanwhile, the trade information is not open to the traders, it is decentralized and the data credibility is low. The database of central structure can easy to attack with no perceive.

Secondly, the electricity market is mainly concentrated in the province area, the operation efficiency is low, which is not facilitated for the regional market developed in a wider scope, it also restrict the resources allocation between each provinces and reject the development of economic industry.

\subsection{Ethernet square Intelligent Contract}

The technology mentioned in the previous section is supported the platform, with the characteristics of weak centralized, data security and cannot be tampered with, it is open and transparent to query, reliable, support disposing a large number of data and storage, it is with higher automatic execution and the management cost reduced, about all, it is considered to design system using Ethernet and intelligent contract. The relevant conceptions is giving as follows.

Blockchain is a new technology, which is developed gradually with the digital encryption currency bitcoin, it provides a credit establishment form with decentralized and dispensed with no credit accumulation paradigm [7] [26].

According to establish an all maintained and no tampered database to record all the trade recordings and historical data, all data are stored distributed and public. In essence, it is a bunch of data block linked together, each data block record a special set of trade status information with arborescence feature, then combined with distributed database and timestamp techniques, it can ensure the block safety and the trade data cannot be tampered. Under this technology, any unknown network users can reach an agreement according to contract, point to point accounting and digital encryption methods, which is completed without any central trust institutions [7] [27] [28].

The platform used in this paper is ethereum, which is the intelligent contract development platform based on blockchain. The ethereum include external accounts and contract accounts, among these, the contract accounts can be controlled by the code of stored accounts. When a message is sent from one account to another, there would be a trade executed and the code and input data in the target account will be executed too [29].

The smart contract writing with ethereum can realize self-conduct and validate once established and deployed, it does not require human intervention, and produced verifiable evidence to demonstrate the effectiveness of contract operation [30]. It can realize a contract which with clear logic, easy to test, clear responsibility and simple to find out responsibility. The malicious or unexpected incident would take place reducing to minimum, the demand of trust intermediary become low, and also reduce the loss caused by cheat [7].

\section{Application feasibility of Blockchain in Schedule system}

We adopt the mode of "contract plus bid" to build an integrated electricity market trading platform composited the regional market and the provincial electricity market.

It integrated different levels of trading within the same system, it can ensure the power supply and demand balance inter provinces in prior when signed contract volume, the provinces can share the Surplus-deficit electricity and bidding price, it can execute competitive price trade in region and achieve efficient market trading. Here, it adopted the smart tract based on ethereum, the trade process is executed automatically according to the established rules, the labor cost in system maintenance can be reduced, and the credibility of trade has also increased. The whole trade data system is decentralized, the trade information can be searched by both sides of trade at any time, and the data cannot be tampered, then it can ensure the trade fair, justice and open.

In summary, we constructed the safe and efficient electric power market trading system, it can realize the trade data out of tampering and inquire safely which the electricity can allocated fairly in large scale region market, improve the production efficiency and accelerated the development of electricity industry. 


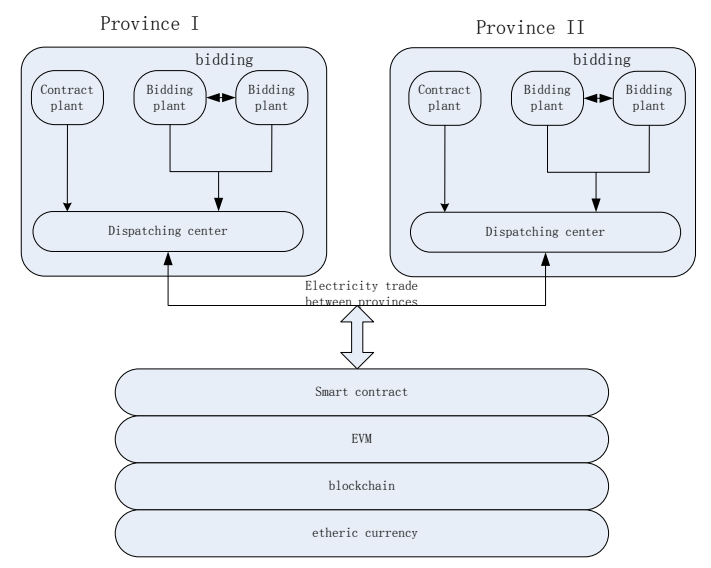

Fig. 1. Actual system framework.

This work used the Solidity language to write smart contracts and uses it as a technical support to build an impeccable competitive cross regional electricity market system. Among them, the smart contract is a deployed on blockchain and can run on ethereum machine. The competitive regional electricity market system constructed in this paper can realize the intra provincial contract electricity, bidding electricity trading and inter provincial electricity trading in the electricity market. The actual system diagram is shown in figure 1 .

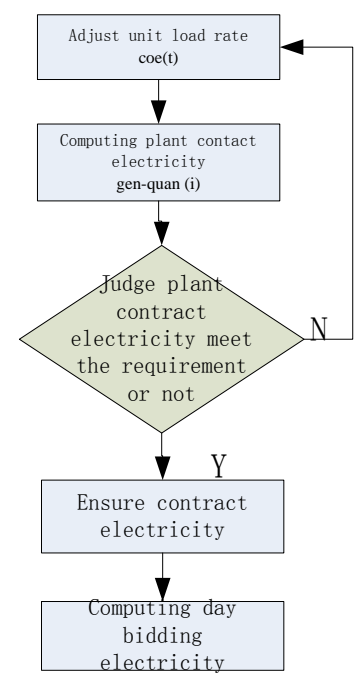

Fig. 2. Contract power allocation algorithm.

According to the existing electricity market operating conditions, the contract power generally accounts for $70 \%$ to $90 \%$ of the total pre load. The distribution of contract electricity in province is used hourly rolling distribution algorithm based on the daily load forecast, and the contract power is allocated to the corresponding power plants in an hour basis.

The flow chart of the contract allocation algorithm is shown in figure 2. First of all, it can adjust the unit load rate according to the unit actual situation in each power plant, calculate the plant distributed contract power according to load rate, if the contract distributed electric of each plant can meet the demand of actual contract, the calculation should be concluded, whether or not, then it return to adjust the unit load rate. Repeat the abovementioned process unit the contract power meets the contract requirements.

The calculation steps are as follows:

- Calculated the load rate of plant completed contract electricity at t period time (in hours),

$$
\operatorname{coe}(\mathrm{t})=\frac{\operatorname{load}_{(\mathrm{t}) \times \operatorname{coe}_{\text {all }}}}{\operatorname{gen}_{\max }(\mathrm{t})} \square \square
$$

In the upper model, coe $(t)$ denote the plant completed contract electricity load rate during the t period, load $(t)$ indicated the system load of all the power plants during the $\mathrm{t}$ period, coe $_{\text {all }}$ indicated the adjustment factor, gen $_{\text {all }}(t)$ indicated the maximum output of all the power plants during $t$ period.

- Determine the power plant electricity contract at contract day:

gen_quan(i) $=\sum_{t=1}^{T}$ gen_unit $(\mathrm{i}, \mathrm{t}) \times \Delta \mathrm{t}$

In the upper model, gen_quan(t) is the daily contract electricity quantity of power plant i, gen_unit( $i, t)$ indicated the basic output of power plant i in time t, $\Delta t$ indicated time period. It is to determine whether the contract power of all power plants can meet the contract requirements, if the power plant fails to meet the trading contract requirements, then it can adjusted $\mathrm{coe}_{\text {all }}$, recalculated (1) until all the power plants meet the requirements.

Calculated raval $_{\text {day }}$ the daily bidding power, that is, the difference between the pre load load $_{d a y}$ and the power plant contract power.

\section{Conclusion}

The State Grid is implementing power grid reform, it hopes to establish a competitive electricity market, but the present trade is still remained at the provincial level of internal market, it is weak in connections between regions, the trade between provinces electric resource trade is limited.

The electricity market trade model proposed here can support the multi trade between the power generation and the purchasing power within the province and inter province range. In order to maintain power system stability, the trade will be divided into two parts of contract and bidding, the provinces and plant can be considered as two-stage unit, the provinces market complete its inter electricity trade in priority, the surplusdeficit part is balanced by large scale region market. It integrated the provincial and regional trading of electricity markets, and promoted the coordination and distribution of power resources in a large scale, it plays a role of market regulation and promotes the healthy development of the power industry.

\section{Acknowledgment}


The authors wish to thank cooperators and other co-workers. This work was supported in part by a grant from the program of "Research and application of key technologies in interprovincial surplus renewable energy spot market”.

\section{References}

1. The history of China LJ, Korea electric power market status and prospects of. automation of electric power, 2, 1-4 (2000)

2. China coal network. New electricity reform over the past two years, the challenges are still many, [EB/OL]., http://www.cctd.com.cn/show-, 19166296-1.html, (2017)

3. Chen Zheng. Reflections on the construction of regional electricity market. China Energy News, (2017)

4. Tai Xue, Sun Hongbin, Guo Qinglai. Power chain trading and congestion management method based on block chain in power Internet. power system technology, 40 (2016)

5. Zhang Xin Hua, ye Ze. Equilibrium analysis of electricity market. (China Electric Power Press, Beijing, 2013)

6. Xiang Yang. Logic of the structural change of China's electricity market. productivity study, 6, 2224 (2011)

7. Zou Jun, Zhang Haining, Tang Yi, Li Lei. The blockchain technology guide. (Mechanical Industry Press, Beijing, 2017)

8. Zhu Jizhong. Analysis of the development and implementation of American power market. South China power grid technology, 5, 22-28+101 (2016)

9. Liu Gang. The inspiration of the electricity market reform in Ontario, Canada. China prices, 7, 47-50 (2006)

10. Yuan Jian. Comparison and reference of foreign power market structure. Shandong University, (2014)

11. Cold yuan, Chen Zheng, Ou Peng, Wang Qinghong, Mongolian Sichuan. The latest UK electricity market reform act and Its Enlightenment to China. China energy, 4, 12-15 (2014)

12. Bao Minglei, Ding Yi, Shao Changzheng, Song Yonghua. Review of the Nordic electricity market and its experience for our country. Proceedings of the Chinese Academy of Electrical Engineering: 111.

13. Luan Fengkui, Jia Junguo, Han Yinghao, Zhou Wenyu, Zeng Zeng. Japan's power industry reform and its reference to China's power market construction. East China power, 9, 6-9 (2006)

14. Weican. Sun Kang Jianing electric power industry reform, the market mechanism and international comparison of. Chinese energy, 25, 21 (2016)

15. Chang Dongling, Tu Jin, Cheng Xiaolei. Lessons from the American electricity market in California and its implications for the reform of China's electricity market. power technology and economics, 4, 25-27 (2006)

16. CPC Central Committee and the State Council. Some opinions on further deepening the reform of power system. wind energy industry, 4, 7-11, (2015)

17. Luo Juan. Power system reform, No. 9, depth of interpretation,

http://www.qianzhan.com/analys, t/detail/220/161113-f6400890.html, 2016-11-13.

18. Sales of electricity industry alliance. National electricity reform case of large - sort - Guangdong power market analysis, [EB/OL], http://shoudian.bjx.com.cn/news/20170527/827867.s html, 2017-05-27.

19. Sales of electricity industry alliance. National electricity reform case of large - sort - Shandong power market analysis, [EB/OL]., http://shoudian.bjx.com.cn/news/20170526/827629.s html, 2017-05-26.

20. Sales of electricity industry alliance. National electricity reform case of large - sort - Shanxi power market analysis, [EB/OL]., http://shoudian.bjx.com.cn/news/20170525/827443.s html, 2017-05-25.

21. Sales of electricity industry alliance. National electricity reform case of large - sort - Anhui power market analysis, [EB/OL]., http://shoudian.bjx.com.cn/news/20170524/827210.s html, 2017-05-24.

22. Sales of electricity industry alliance. National electricity reform case of large - sort - Sichuan power market analysis, [EB/OL], http://shoudian.bjx.com.cn/news/20170523/826957.s html, 2017-05-23.

23. Sales of electricity industry alliance. National electricity reform case of large - sort - Jiangxi power market analysis, [EB/OL]., http://shoudian.bjx.com.cn/news/20170522/826681.s html, 2017-05-22.

24. National Power Grid Corp. 2017 1-3, power industry operation profile [EB/OL], http://www.sgcc.c, om.cn/xwzx/nyzx/2017/04/339333.shtml, 2017-0417.

25. Song, song, Current situation and construction of power market in China. electric society, 8, 20-21, (2016)

26. Nakamoto S. Bitcoin: A Peer-to-Peer Electronic Cash System[EB/OL]. https://bit coin.org/bitcoin.pdf, 2008-10.

27. Nakamoto, S., Bitcoin:, A, Peer-to-Peer, Electronic, Cash, $\quad$ System[EB/OL]., https://bit, coin.org/bitcoin.pdf, 2008-10.

28. Narayanan A., Bonneau J., Felten E. Bitcoin and Cryptocurrency Technologies: A Comprehensive Introduction. (Princeton University Press, United States, 2016)

29. Narayanan, A., Bonneau, J., Felten, E., Bitcoin, and, Cryptocurrency, Technologies:, A, Comprehensive,, 
Introduction, Princeton, University, Press, United, States)

30. Yuan Yong, Wang Feiyue. Block chain development present situation and prospects of. Journal of automation, 4, 481-494, (2016) 